Check for updates

Cite this: RSC Adv., 2018, 8, 26047

Accepted 5th July 2018

DOI: $10.1039 / c 8 r a 04091 e$

rsc.li/rsc-advances
Received 14th May 2018

\section{Size-controllable synthesis of $\mathrm{NiCoSe}_{2}$ microspheres as a counter electrode for dye- sensitized solar cells}

\author{
Xiaobo Chen, (D) *a Jingguo Ding, ${ }^{a}$ Yan Li, ${ }^{\text {a }}$ Yinxia Wu, ${ }^{a}$ Guoce Zhuang, ${ }^{a}$ Cuicui Zhang, ${ }^{a}$ \\ Zhihai Zhang, ${ }^{a}$ Chengyun Zhu ${ }^{a}$ and Peizhi Yang ${ }^{\star b}$
}

$\mathrm{NiCoSe}_{2}$ microspheres have been successfully synthesized by a facile one-step hydrothermal method at different hydrothermal temperatures. The prepared samples are divided according to their reaction temperatures $\left(90,120,150\right.$ and $180{ }^{\circ} \mathrm{C}$ ) and named $\mathrm{NiCoSe}_{2}-90, \mathrm{NiCoSe}_{2}-120, \mathrm{NiCoSe}-150$ and $\mathrm{NiCoSe}_{2}-180$, respectively. The diameters of the $\mathrm{NiCoSe}_{2}$ microspheres strongly depend on the different hydrothermal temperatures. When the temperature is increased to $150{ }^{\circ} \mathrm{C}$, the size of the resultant $\mathrm{NiCoSe}_{2}$ microspheres changes from 200 to $800 \mathrm{~nm}$, and the interior of $\mathrm{NiCoSe}_{2}-150$ possesses a flocculent structure. However, NiCoSe $2-180$ displays a cauliflower-like aggregated structure. The prepared $\mathrm{NiCoSe}_{2}$ alloys are used as high-performance Pt-free counter electrodes (CEs) for dyesensitized solar cells (DSSCs). Cyclic voltammogram measurement indicates that $\mathrm{NiCoSe}_{2}-150 \mathrm{CE}$ has larger current density than Pt CE. Electrochemical impedance spectroscopy shows that $\mathrm{NiCoSe}_{2}-150 \mathrm{CE}$ has a low charge-transfer resistance of $1.8 \Omega \mathrm{cm}^{2}$. Due to their unique morphologies and well-defined interior and exterior structures, DSSCs based on $\mathrm{NiCOSe}_{2}-120$ and $\mathrm{NiCoSe}_{2}-150$ CEs achieve high power conversion efficiencies of $8.48 \%$ and $8.76 \%$, respectively, which are higher than that of the solar cell based on Pt CE (8.31\%)

\section{Introduction}

Dye-sensitized solar cells (DSSCs) are regarded as a new type of promising solar cells because of their environmental friendliness, low cost, easy preparation processes and good photovoltaic performance..$^{1-3} \mathrm{~A}$ typical DSSC usually consists of a counter electrode (CE), a dye-loaded $\mathrm{TiO}_{2}$ photoanode and a triiodide/ iodide $\left(\mathrm{I}^{-} / \mathrm{I}_{3}{ }^{-}\right)$redox electrolyte. The main role of $\mathrm{CE}$ is to collect the electrons from the external circuit and return them back to the redox electrolyte and catalyze the reduction of $\mathrm{I}_{3}{ }^{-}$to $\mathrm{I}^{-}$at the $\mathrm{CE} /$ electrolyte interface. ${ }^{4,5} \mathrm{Pt}$-coated fluorine-doped tin oxide (FTO) glass is often used as CE in a general DSSC, which shows high performance due to its excellent conductivity, outstanding electrocatalytic activity and good chemical stability. However, until now, the most limiting factors in the development of commercial DSSCs have been their cost and long-term stability. The large-scale application of Pt CE in commercial DSSCs is limited, which has greatly stimulated the research of stable and effective Pt-free CE materials with low

${ }^{a}$ School of New Energy and Electronic Engineering, Yancheng Teachers University, Yancheng, 224051, PR China. E-mail: chenxbok@126.com

${ }^{b}$ Key Laboratory of Education Ministry for Advance Technique and Preparation of Renewable Energy Materials, Institute of Solar Energy, Yunnan Normal University, Kunming, 650500, PR China. E-mail: pzhyang@hotmail.com cost, high conductivity and electrocatalytic activity for the reduction of $\mathrm{I}_{3}{ }^{-} \cdot{ }^{6,7}$

Several low-cost materials with excellent performances, such as alloys, ${ }^{8,9}$ transition metal compounds, ${ }^{4,10,11}$ carbonaceous materials, ${ }^{12,13}$ composites, ${ }^{14,15}$ and conductive polymers, ${ }^{16,17}$ have been successfully utilized as Pt-free CEs in DSSCs. Among these Pt-free CE materials, metal selenides are competitive candidates because of their outstanding electrocatalytic activity for triiodide reduction., ${ }^{418-20}$ A hollow NiSe- $\mathrm{Ni}_{3} \mathrm{Se}_{2}$ hybrid nanostructure composite was also directly synthesized on reduced graphene oxide in situ; the NiSe series exhibited a high PCE value of $7.87 \% .{ }^{21}$ Profiting from the coexistence of Ni and Co in Ni-Co selenides, ternary selenides offer richer redox reactions than NiSe and CoSe. For example, $\left(\mathrm{Ni}_{1-x} \mathrm{Co}_{x}\right) \mathrm{Se}_{2}$ nanoparticles were synthesized via a one-step hydrothermal reduction route, and the obtained sample could exhibit better electrocatalytic properties compared to $\mathrm{NiSe}_{2}, \mathrm{CoSe}_{2}$ and Pt. ${ }^{22}$ Moreover, it is generally acknowledged that stoichiometric ratio and morphology are the two main factors that affect the catalytic activity of $\mathrm{CE}$ materials.

Herein, $\mathrm{NiCoSe}_{2}$ microspheres were prepared by a one-step facile hydrothermal method at different hydrothermal temperatures, and they were used as CE materials for DSSCs. The size of the microspheres increased with the increase in the reaction temperature, and the microspheres exhibited agglomeration. Meanwhile, the $\mathrm{NiCOSe}_{2}-150$ sample exhibited the most porous 
features. The overall energy conversion efficiency of the DSSC with $\mathrm{NiCoSe}_{2}-150 \mathrm{CE}$ reached $8.76 \%$, and DSSCs with $\mathrm{NiCoSe}_{2}$ 120 and $\mathrm{NiCoSe}_{2}-180$ CEs achieved power conversion efficiencies (PCE) of $8.48 \%$ and $8.31 \%$, respectively. PCEs of the cells based on the above-mentioned three $\mathrm{NiCoSe}_{2} \mathrm{CEs}$ were superior to that of Pt CE-based DSSC (8.22\%).

\section{Experimental}

\subsection{Preparation of $\mathrm{NiCoSe}_{2}$ microspheres}

$\mathrm{NiCoSe}_{2}$ microspheres were synthesized via a facile one-step hydrothermal method. First, $1 \mathrm{~mol}$ of $\mathrm{NiCl}_{2} \cdot 6 \mathrm{H}_{2} \mathrm{O}, 1 \mathrm{~mol}$ of $\mathrm{CoCl}_{2} \cdot 6 \mathrm{H}_{2} \mathrm{O}$ and $0.2 \mathrm{~mol}$ of cetyl trimethylammonium bromide (CTAB) were mixed in $30 \mathrm{~mL}$ of distilled water. To this solution, 2 mol of Se powder was added and magnetically stirred for $15 \mathrm{~min} ; 20 \mathrm{~mL}$ of $\mathrm{N}_{2} \mathrm{H}_{4} \cdot \mathrm{H}_{2} \mathrm{O}$ was then added drop-wise to the reaction mixture on vigorous stirring for $30 \mathrm{~min}$. After ultrasonic oscillation for $20 \mathrm{~min}$, the resulting mixture was transferred to a Teflon-lined stainless-steel autoclave. The hydrothermal temperatures were set at $90,120,150$ and $180{ }^{\circ} \mathrm{C}$ for $24 \mathrm{~h}$. After cooling to room temperature, the product was centrifuged, cleaned repeatedly with distilled water and absolute ethanol to remove residual chemicals and then dried in a vacuum oven at $80{ }^{\circ} \mathrm{C}$ for $6 \mathrm{~h}$. The obtained products were labeled as $\mathrm{NiCoSe}_{2}-$ 90, $\mathrm{NiCoSe}_{2}-120, \mathrm{NiCoSe}_{2}-150$ and $\mathrm{NiCoSe}_{2}-180$.

\subsection{Preparation of counter electrodes}

The counter electrodes of $\mathrm{NiCoSe}_{2}$ with different reaction temperatures were spread on cleaned FTO glass by spin-coating. First, $5 \mathrm{mg}$ of the corresponding $\mathrm{NiCoSe}_{2}$ powder was put into $0.5 \mathrm{~mL}$ of absolute alcohol; after ultrasonic stirring for $30 \mathrm{~min}$, a well-dispersed solution was formed. Then, the resulting $\mathrm{NiCoSe}_{2}$ dispersion solution was coated on the cleaned FTO glass by spin-coating with a rotation rate of $500 \mathrm{rpm}$ for $15 \mathrm{~s}$. After drying at $80{ }^{\circ} \mathrm{C}$ for $5 \mathrm{~min}$, a second layer of $\mathrm{NiCoSe}_{2}$ was subsequently coated over the first layer. Then, a third layer was also deposited on the previous layer in the same way. After the deposition of the three layers, the coated FTO glass was dried at $140{ }^{\circ} \mathrm{C}$ for $15 \mathrm{~min}$. The thickness of each electrode on the FTO glass was about $4 \mu \mathrm{m}$. A commercial Pt electrode (Dalian HepatChroma Solar Tech. Co., Ltd.) was used as a reference.

\subsection{Fabrication of DSSCs}

$\mathrm{TiO}_{2}$ photoanodes were prepared on an FTO glass substrate (7 $\Omega$ per square) by using the conventional screen-printing method. ${ }^{23}$ A $\mathrm{TiO}_{2}$ film $(\sim 12 \mu \mathrm{m})$ was coated on the FTO glass as a transparent nanocrystalline-sensitized $\mathrm{TiO}_{2}$ layer using commercial $20 \mathrm{~nm} \mathrm{TiO}_{2}$ pastes (Dalian HepatChroma Solar Tech. Co., Ltd., China). Also, a light-scattering layer with about $4 \mu \mathrm{m}$ thickness was applied on top of the transparent layer by using commercial $200 \mathrm{~nm} \mathrm{TiO}_{2}$ pastes (Dalian HepatChroma Solar Tech. Co., Ltd., China). Then, the $\mathrm{TiO}_{2}$ photoanodes were sintered at $500{ }^{\circ} \mathrm{C}$ for $1 \mathrm{~h}$ before being treated with $0.04 \mathrm{M}$ titanium tetrachloride $\left(\mathrm{TiCl}_{4}\right)$ aqueous solution at $70{ }^{\circ} \mathrm{C}$ for $1 \mathrm{~h}$. Finally, the $\mathrm{TiO}_{2}$ photoanodes were annealed again at $500{ }^{\circ} \mathrm{C}$ for $1 \mathrm{~h}$. The $\mathrm{TiO}_{2}$ films were sensitized by immersing in $0.50 \mathrm{mM}$ solution of N719 dye in ethanol for $12 \mathrm{~h}$. The DSSC was assembled into a sandwich structure with the dye-sensitized $\mathrm{TiO}_{2}$ electrodes, the electrolyte and a Pt sputtered conducting glass. In addition, a drop of the electrolyte solution (10 $\mathrm{mM}$ of LiI, $1 \mathrm{mM}$ of $\mathrm{I}_{2}$, and $0.1 \mathrm{mM}$ of $\mathrm{LiClO}_{4}$ in acetonitrile) was injected into the clamped electrodes. The active area of the test devices was limited to 0.25 $\mathrm{cm}^{2}$. A total of ten cells for each investigated CE were fabricated to obtain a representative result.

\subsection{Instruments and characterizations}

$\mathrm{X}$-ray diffraction (XRD) measurements were performed on an Xray powder diffractometer (Smartlab-9 X-ray diffractometer, Rigaku, Japan) at $40 \mathrm{kV}$ and $40 \mathrm{~mA}$ with $\mathrm{Cu} \mathrm{K} \alpha(\lambda=1.5418 \AA)$ in the range of $10-80^{\circ}(2 \theta)$. Scanning electron microscopy (SEM) was carried out with a Zeiss Supra 35VP instrument coupled with energy-dispersive X-ray spectroscopy (EDS) operating at 10 $\mathrm{kV}$. X-ray photoelectron spectroscopy (XPS) was performed on ESCALAB 250XI (Thermo Fisher Scientific, America) using Mg $\mathrm{K} \alpha$ radiation as the excitation source.

Electrochemical analyses, including cyclic voltammetry (CV) measurements, Tafel polarization curves and electrochemical impedance spectroscopy (EIS), were conducted on an electrochemical workstation (CHI660E, Shanghai Chenhua Device Company, China). Cyclic voltammetry measurements were performed in a three-electrode system in an acetonitrile solution of $1 \mathrm{mM} \mathrm{I}_{2}, 10 \mathrm{mM} \mathrm{LiI} \mathrm{and} 100 \mathrm{mM} \mathrm{LiClO}_{4}$, and the potential range was set from $-0.6 \mathrm{~V}$ to $1.2 \mathrm{~V}$ at a scan rate of $50 \mathrm{mV} \mathrm{s}^{-1}$. The FTO glass coated with the catalyst was used as the working electrode; a Pt foil and an $\mathrm{Ag} / \mathrm{AgCl}$ electrode were used as the counter electrode and the reference electrode, respectively. Tafel polarization curves and electrochemical impedance spectroscopy results were obtained using a symmetrical cell consisting of two same $\mathrm{NiCoSe}_{2}$ alloy electrodes (CE/electrolyte/CE). EIS was performed in the frequency range from $100 \mathrm{kHz}$ to $100 \mathrm{mHz}$ with $5 \mathrm{mV}$ amplitude. Tafel polarization curves were scanned from -1.0 to $1.0 \mathrm{~V}$ with a scan rate of $10 \mathrm{mV} \mathrm{s}^{-1}$. Moreover, the resultant impedance spectra were analyzed by the Z-view software. The incident photon conversion efficiencies (IPCE) were obtained using a Keithley 2000 SourceMeter under the irradiation of a $150 \mathrm{~W}$ xenon lamp (Oriel) fitted with a monochromator (Cornerstone 74004) as the monochromatic light source. The photocurrent-voltage $(J-V)$ characteristics of DSSCs based on the as-prepared CEs and commercial Pt/FTO CE were conducted by a standard solar simulator (Xe Lamp Oriel $\mathrm{Sol}^{3} \mathrm{~A}^{\mathrm{TM}}$ Class AAA Solar Simulators 94023A, USA) under irradiation of simulated solar light at ambient atmosphere. The $J-V$ curves were also recorded by the CHI660E electrochemical workstation.

\section{Results and discussion}

\subsection{Morphology and composition}

The XRD patterns of $\mathrm{NiCoSe}_{2}$ alloys with different hydrothermal temperatures are shown in Fig. 1. It is clearly seen that the four samples show similar XRD patterns except for the $\mathrm{NiCoSe}_{2}-90$ sample, which exhibits low crystallinity. The diffraction peaks of 


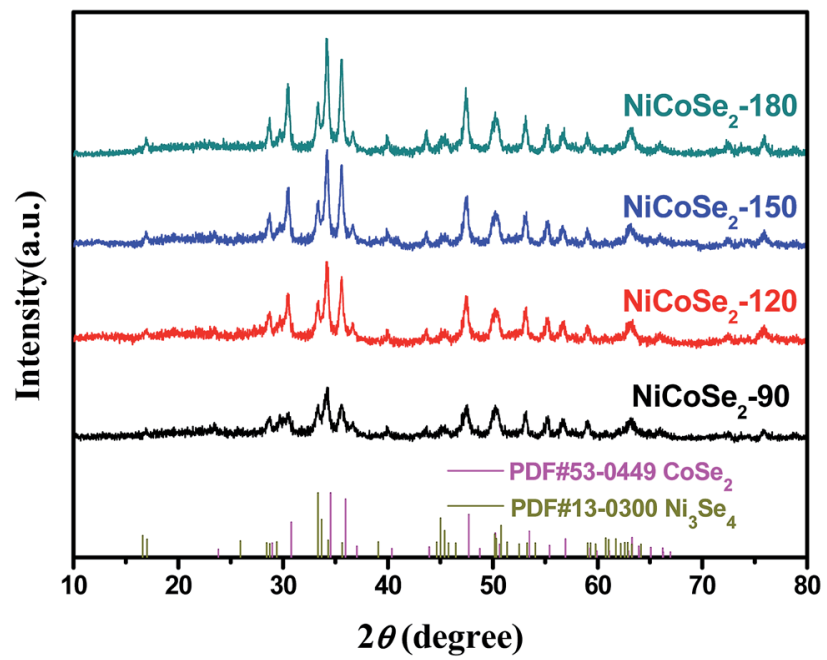

Fig. 1 XRD patterns of the samples $\mathrm{NiCoSe}_{2}-90, \mathrm{NiCoSe}_{2}-120$, $\mathrm{NiCoSe}_{2}-150$ and $\mathrm{NiCoSe}_{2}-180$.

$\mathrm{NiCoSe}_{2}-90, \mathrm{NiCoSe}_{2}-120$, and $\mathrm{NiCoSe}_{2}-150$ can be readily indexed to orthorhombic $\mathrm{CoSe}_{2}$ (JCPDS card no. 53-0449) ${ }^{21}$ and a small fraction of monoclinic $\mathrm{Ni}_{3} \mathrm{Se}_{4}$ (JCPDS card no. 13-0300). ${ }^{7}$ It is clear that there are no other peaks in the patterns, which indicates that the prepared products are of pure quality. Several well-resolved peaks appear at $23.8^{\circ}, 28.7^{\circ}, 30.5^{\circ}, 34.2^{\circ}, 35.6^{\circ}, 37.0^{\circ}, 40.1^{\circ}$, $43.6^{\circ}, 47.5^{\circ}, 50.2^{\circ}, 53.2^{\circ}$ and $63.1^{\circ}$ corresponding to orthorhombic $\mathrm{CoSe}_{2}$ (110), (011), (101), (111), (120), (200), (210), (121), (211) (002), (031) and (122). These peaks also match well with the reported data. ${ }^{24}$ The peaks at around $16.9^{\circ}, 33.4^{\circ}, 45.4^{\circ}, 50.2^{\circ}$ and $53.2^{\circ}$ corresponding to the (002) (202), (204) (020) and (002) crystal planes of monoclinic $\mathrm{Ni}_{3} \mathrm{Se}_{4}$ are observed. The XRD patterns of the as-prepared $\mathrm{NiCoSe}_{2}$ powders mainly consist of two phases, i.e., orthorhombic CoSe $e_{2}$ and a small amount of monoclinic $\mathrm{Ni}_{3} \mathrm{Se}_{4}$. Hence, $\mathrm{NiCoSe}_{2}$ alloys with nearly same crystal structures have been successfully prepared. In addition, the peak intensity increases with the increasing hydrothermal temperature, indicating improved crystallization and particle size growth; these results will be confirmed by SEM results shown later.

SEM images were obtained for the investigation of the structural morphologies of the synthesized samples. As shown in Fig. 2a, $\mathrm{NiCoSe}_{2}-90$ was composed of a large number of dense spherical particles with a diameter of about $200 \mathrm{~nm}$. When the hydrothermal temperature was increased to $150{ }^{\circ} \mathrm{C}$, the size of $\mathrm{NiCoSe}_{2}$ spheres became larger; this was consistent with the XRD analysis. The SEM image of $\mathrm{NiCoSe}_{2}-150$ (Fig. 2c) revealed that $\mathrm{NiCoSe}_{2}$ spheres with a diameter of about $800 \mathrm{~nm}$ were obtained as some of the spheres were partially broken, which can be clearly observed from the flocculent structure of the assynthesized $\mathrm{NiCoSe}_{2}$ spheres. Moreover, the unique flocculent structure of the $\mathrm{NiCoSe}_{2}-150$ sample could provide effective transport pathways for electrons and ions, which enhanced the electrochemical kinetics. However, $\mathrm{NiCoSe}_{2}-180$ (Fig. 2d) displayed a cauliflower-like aggregated structure since the spheres were connected to each other, and it was difficult to separate out a single sphere, which might have been affected by the relatively high temperature of the hydrothermal process. The atomic ratios of the prepared $\mathrm{Ni}-\mathrm{Co}-\mathrm{Se}$ alloys were determined by EDS using $\mathrm{NiCoSe}_{2}-150$ as a representative sample. The elemental concentrations of $\mathrm{Ni}$, Co and $\mathrm{Se}$ in the film were ascertained as 25.1, 27.3 and 47.6, respectively. This ratio was close to the composition of $\mathrm{NiCoSe}_{2}(1: 1: 2)$. Furthermore, as can be seen in Fig. 2e-h, Ni, Co and Se elements displayed a uniform distribution in the mapping diagram, which further confirmed that the Ni-Co-Se alloys have been successfully synthesized. The TEM image (Fig. 2j) further confirmed the sphere size and the overall morphology of $\mathrm{NiCoSe}_{2}-150$. The typical HRTEM image (the inset of Fig. 2j) revealed clear lattice fringes separated by $0.371 \mathrm{~nm}$ and $0.266 \mathrm{~nm}$, corresponding to the (110) plane of orthorhombic $\mathrm{CoSe}_{2}$ and the (202) plane of monoclinic $\mathrm{Ni}_{3} \mathrm{Se}_{4}$, which agreed well with the XRD results.

To investigate the chemical bonding states and the elemental components of the $\mathrm{NiCoSe}_{2}$ alloy, the sample was examined by Xray photoelectron spectroscopy (XPS). The $\mathrm{NiCoSe}_{2}-150$ sample was selected as a representative sample. As shown in Fig. 3a, the survey spectrum confirmed the presence of $\mathrm{C}, \mathrm{O}, \mathrm{Ni}$, Co and Se in the product. The $\mathrm{C} 1 \mathrm{~s}$ peak and the $\mathrm{O} 1 \mathrm{~s}$ peak appeared because the surface was exposed in ambient conditions, and it adsorbed other elements inevitably, which indicated that the near-surface of the $\mathrm{NiCoSe}_{2}-150$ sample mainly comprised $\mathrm{Se}, \mathrm{Ni}$, and Co. ${ }^{25}$ Fig. 3b-d show the high-solution XPS spectra of Ni 2p, Co 2p and Se 3d, respectively. The high-solution spectra of Ni $2 \mathrm{p}$ and Co $2 \mathrm{p}$ could be divided into spin-orbit doublets and shakeup satellites (identified as "Sat.") by the Gaussian fitting method. The Ni 2p spectrum of $\mathrm{NiCoSe}_{2}-150$ is shown in Fig. 3b; the fitting peak at 853.3 was assigned to $\mathrm{Ni}^{2+}$, and the peak at $872.5 \mathrm{eV}$ was ascribed to $\mathrm{Ni}^{3+} \cdot{ }^{26,27}$ For the Co spectrum, the first doublet (at 777.9 and $792.6 \mathrm{eV}$ ) and the second doublet (at 779.7 and $795.1 \mathrm{eV}$ ) were the characteristics of $\mathrm{Co}^{3+}$ and $\mathrm{Co}^{2+} \cdot{ }^{25,28}$ Our results showed that the Co and $\mathrm{Ni}$ atoms were in divalent states. Moreover, as shown in Fig. 3d, Se 3d peaks could be deconvoluted into two peaks; the two peaks at $59.2 \mathrm{eV}$ and $55.3 \mathrm{eV}$ could be assigned to $\mathrm{Se} 3 \mathrm{~d}_{3 / 2}$ and $3 \mathrm{~d}_{5 /}$ ${ }_{2}$, respectively, which represented typical metal-selenium bonds. ${ }^{29}$ According to the XPS analysis, it was clear that the surface of the $\mathrm{Ni}-\mathrm{Co}-\mathrm{Se}$ alloy mainly consisted of $\mathrm{Ni}^{2+}, \mathrm{Co}^{2+}$ and $\mathrm{Se}^{2-}$.

\subsection{Electrochemical properties}

To evaluate the electrocatalytic properties of the as-prepared $\mathrm{NiCoSe}_{2}$ microspheres, cyclic voltammetry (CV) and electrochemical impedance spectroscopy (EIS) were carried out. CV was performed to evaluate the reaction kinetics of the $\mathrm{I}^{-} / \mathrm{I}_{3}{ }^{-}$ redox reaction. ${ }^{30}$ As shown in Fig. 4a, all CEs showed two pairs of redox peaks (Red-1/Ox-1, Red-2/Ox-2), of which the redox peaks at the more negative potentials represent the eqn (1) (Red$1 / \mathrm{Ox}-1)$ reaction, and the peaks at the more positive potentials represent the eqn (2) (Red-2/Ox-2) reaction.

$$
\begin{aligned}
& 3 \mathrm{I}_{2}+2 \mathrm{e}^{-} \leftrightarrow 3 \mathrm{I}^{-} \\
& \mathrm{I}_{3}{ }^{-}+2 \mathrm{e}^{-} \leftrightarrow 3 \mathrm{I}^{-}
\end{aligned}
$$

The $\mathrm{I}_{3}{ }^{-}$reduction reaction mainly occurs on the side of $\mathrm{CE}$; thus, the $\mathrm{I}^{-} / \mathrm{I}_{3}{ }^{-}$redox couple was explored in this study. Generally, 

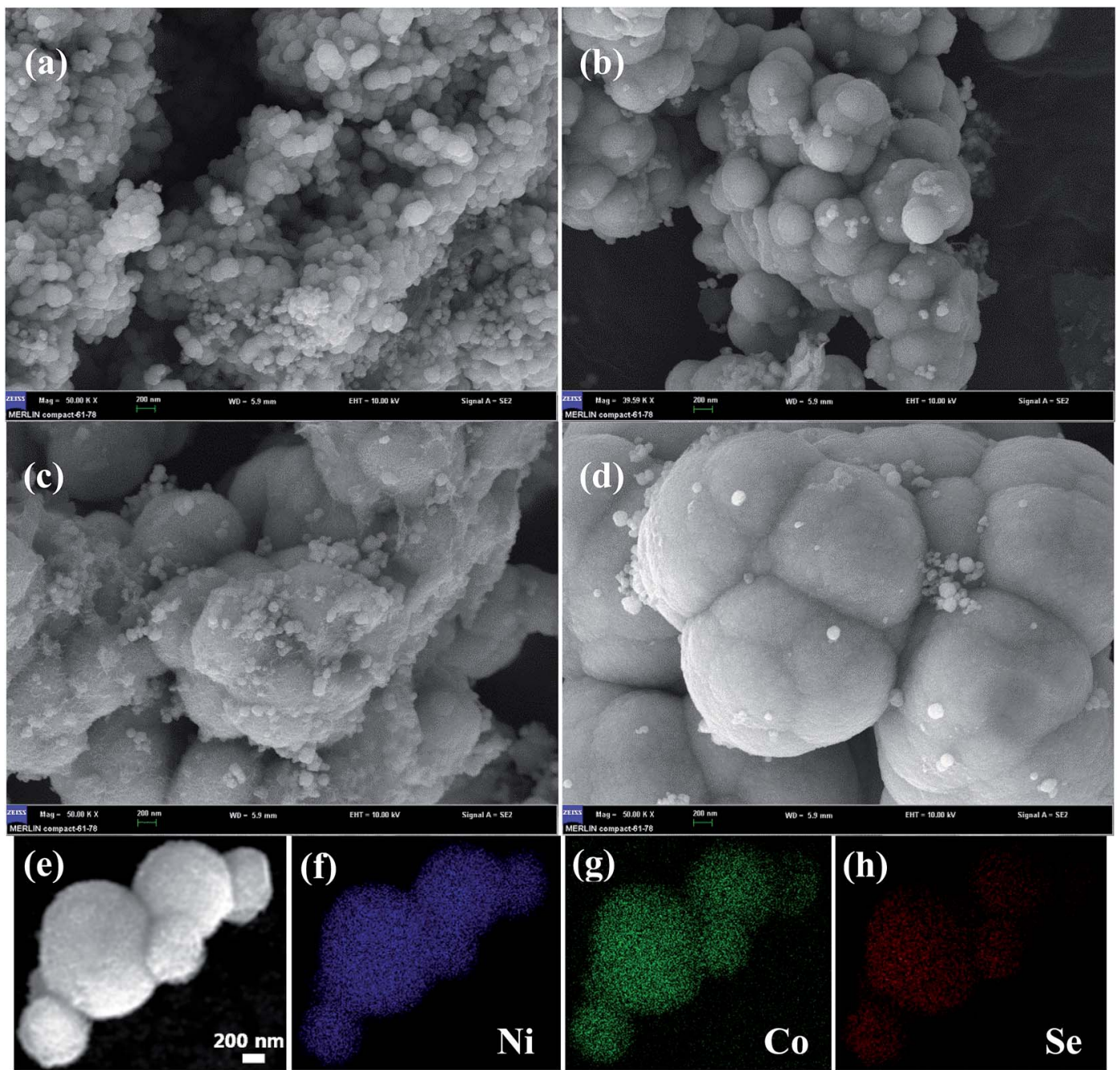

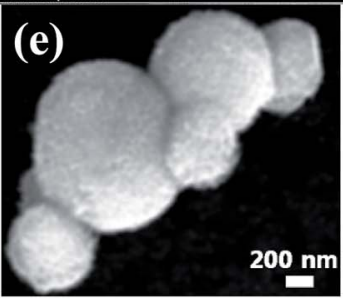

(i)

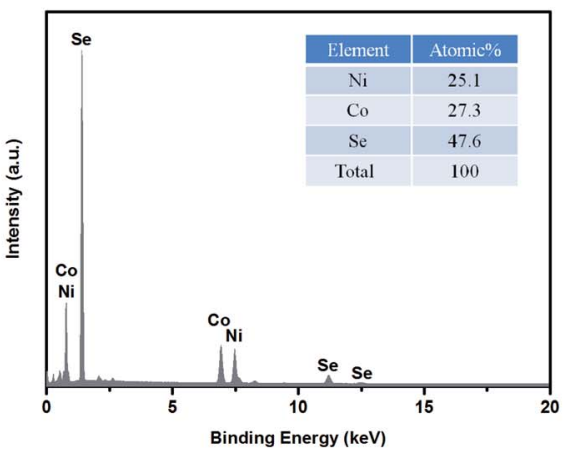

(j)

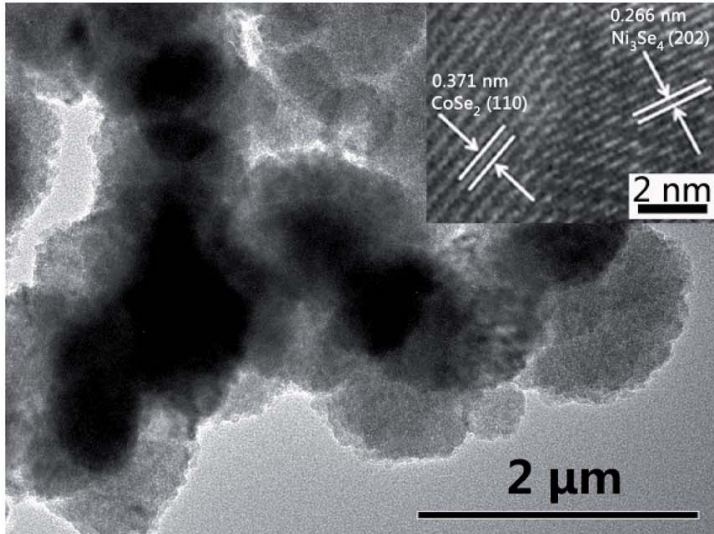

Fig. 2 SEM images (scale bar $=200 \mathrm{~nm}$ ) of $\mathrm{NiCoSe}_{2}$ prepared at different reaction temperatures of (a) $90^{\circ} \mathrm{C}$ (b) $120^{\circ} \mathrm{C}$, (c) $150{ }^{\circ} \mathrm{C}$ and (d) $180{ }^{\circ} \mathrm{C}$. Elemental mapping images (e-h), EDS (i), TEM image (j) and HRTEM (inset of (j)) of $\mathrm{NiCoSe}_{2}-150$.

the peak-to-peak potential separation $\left(E_{\mathrm{pp}}\right)$ between Red-1 and Ox1 and the peak current density of the reduction peak Red-1 $\left(\left|J_{\text {Red- }-1}\right|\right)$ are two crucial parameters in a CV curve. Moreover, the value of $\left|J_{\text {Red-1 }}\right|$ is always utilized to assess the reaction rate of the CE catalyst for the reduction reaction of $\mathrm{I}_{3}^{-}$to $\mathrm{I}^{-}$. A higher peak current density $\left|J_{\text {Red-1 }}\right|$ results in enhanced electrocatalytic activity of the CE material. As shown in Table 1, $\mathrm{NiCoSe}_{2}-150 \mathrm{CE}$ possessed the highest $\left|J_{\text {Red-1 } 1}\right|$ value of $4.31 \mathrm{~mA} \mathrm{~cm}{ }^{-2}$, suggesting that this sample has higher $\mathrm{I}^{-} / \mathrm{I}_{3}{ }^{-}$redox couple electrocatalytic ability compared to Pt $\left(3.59 \mathrm{~mA} \mathrm{~cm}{ }^{-2}\right)$. Moreover, the $\left|J_{\text {Red-1 } 1}\right|$ value of 

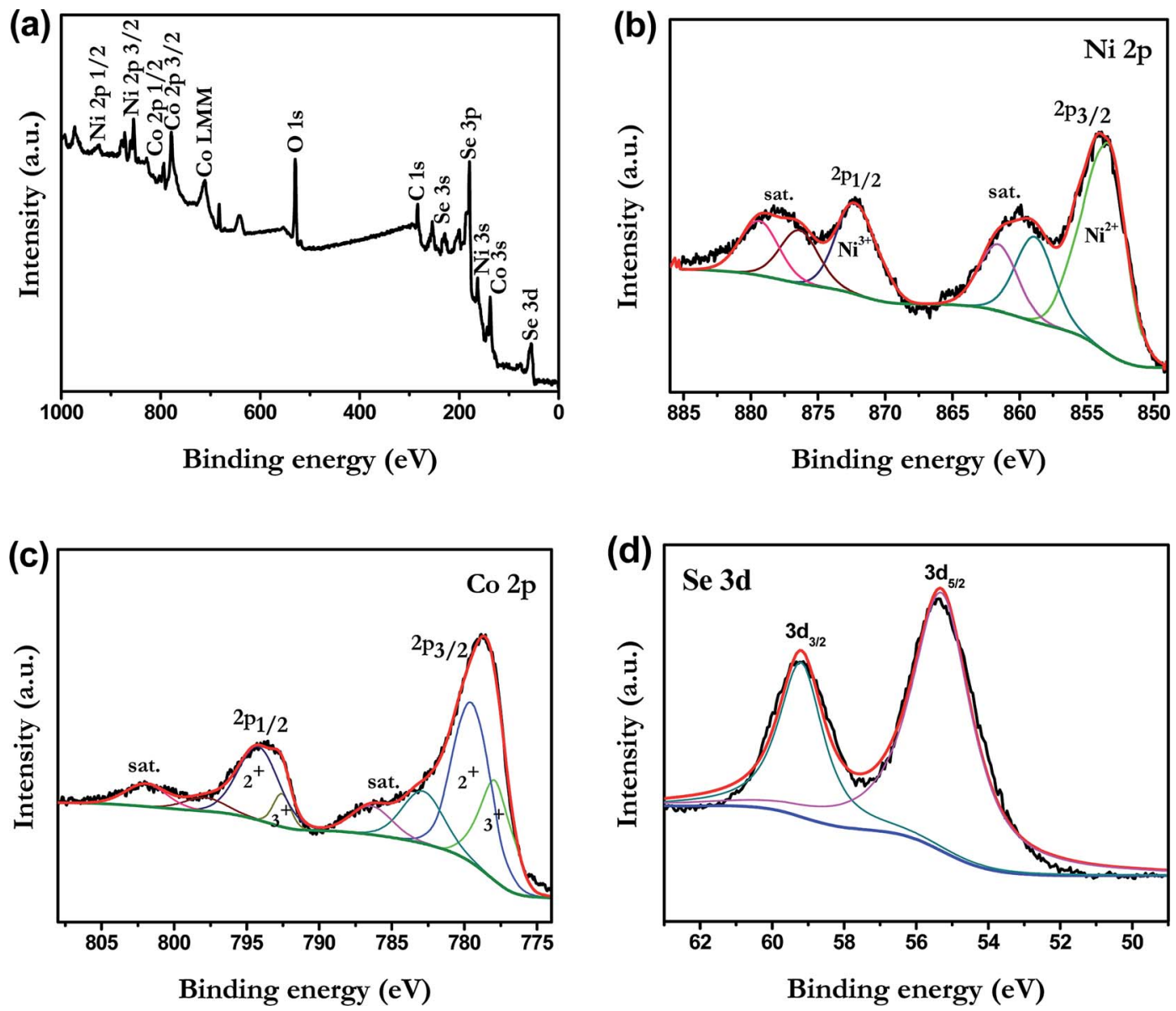

Fig. 3 XPS spectra of NiCoSe -150 : (a) survey spectrum, (b) Ni 2p, (c) Co 2p and (d) Se 3d.

$\mathrm{NiCoSe}_{2}-120$ (3.81 $\mathrm{mA} \mathrm{cm}{ }^{-2}$ ) was slightly larger than that of Pt CE. On the other hand, $E_{\mathrm{pp}}$ is a parameter to evaluate the reversibility of the redox reaction, and a lower $E_{\mathrm{pp}}$ value means better electrocatalytic ability. The $E_{\mathrm{pp}}$ values of CEs increased in the order $\mathrm{NiCoSe}_{2}-150(461 \mathrm{mV})<\mathrm{NiCoSe}_{2}-120(465 \mathrm{mV})<\mathrm{NiCoSe}_{2}-180(487$ $\mathrm{mV})<\mathrm{Pt}(535 \mathrm{mV})<\mathrm{NiCoSe}_{2}-90(633 \mathrm{mV})$. Apparently, $\mathrm{NiCoSe}_{2}-120$ and NiCoSe $\mathrm{N}_{2}-150 \mathrm{CEs}$ showed significantly higher electrocatalytic activities than Pt. Additionally, the highest $\left|J_{\text {Red-1 }}\right|$ and lowest $E_{\mathrm{pp}}$ values indicated that $\mathrm{NiCoSe}_{2}-150 \mathrm{CE}$ has superior electrocatalytic activity for $\mathrm{I}_{3}{ }^{-}$reduction, due to which it can be a better alternative material to Pt CE in DSSCs.

In addition, Fig. $4 \mathrm{~b}$ shows CVs of the $\mathrm{I}^{-} / \mathrm{I}_{3}{ }^{-}$system on the $\mathrm{NiCoSe}_{2}-150$ electrode with different scan rates (i.e., 50, 75, 100 and $125 \mathrm{mV} \mathrm{s}^{-1}$ ). With the increasing scan rate, CVs exhibit a regularly outward extension of all peaks. Fig. 4c illustrates the linear relationship between the peak current density and the square root of the scan rate, indicating that the diffusion of $\mathrm{I}^{-}$ controls the redox reaction on $\mathrm{CE}$ and there is no specific interaction between the prepared $\mathrm{CE}$ and the $\mathrm{I}^{-} / \mathrm{I}_{3}{ }^{-}$redox pair. ${ }^{31}$ To investigate the stability of CE in the liquid electrolyte, CV measurements have been performed on the $\mathrm{CE}$ based on $\mathrm{NiCoSe}_{2}-150$ at a scan rate of $50 \mathrm{mV} \mathrm{s}^{-1}$ for 100 cycles (see Fig. 4d). No apparent decrease in the current density is observed during cycling, indicating that this CE exhibits good electrochemical stability as the CE material for DSSCs.
EIS analysis was conducted using typical symmetrical dummy cells for further characterization of the charge transfer process at the electrolyte/CE interface. Nyquist plots of all cells with Ni-Co-Se alloy CEs (Fig. 5a) showed two semicircles at the low-frequency and the high-frequency regions. The intercept of the high-frequency semicircle with the horizontal axis signifies the series resistance $\left(R_{\mathrm{S}}\right)$, which can be affected by the adhesion of the electrocatalyst film to the FTO glass. The high-frequency semicircle corresponds to the charge transfer resistance $\left(R_{\mathrm{ct}}\right)$ at the $\mathrm{CE} /$ electrolyte interface for the $\mathrm{I}_{3}{ }^{-}$reduction, which is a pivotal parameter reflecting the catalytic activity of the prepared CEs. A smaller value of $R_{\mathrm{ct}}$ stands for a smaller value of the overpotential needed for the electron transfer from CE to electrolyte. $^{32,33}$ The low-frequency semicircle (right-hand side) represents the Warburg diffusion resistance (ZW) within the bulk electrolyte and the electrocatalyst film. The abovementioned parameters were extracted by fitting the EIS spectrum with an equivalent circuit (the inset of Fig. 5a), and the results are shown in Table 1 . As shown in Table 1 , the $R_{\mathrm{S}}$ values of $\mathrm{NiCoSe}_{2}-90, \mathrm{NiCoSe}_{2}-120, \mathrm{NiCoSe}_{2}-150, \mathrm{NiCoSe}_{2}-180$ and Pt were 9.4, 9.6, 9.6, 9.5 and $9.5 \Omega \mathrm{cm}^{2}$, respectively. A larger $R_{\mathrm{S}}$ value indicates weaker adhesion of the electrocatalytic material to the FTO substrate. All $R_{\mathrm{S}}$ values were very close to each other. In addition, $R_{\mathrm{ct}}$ increased in the order NiCoSe $\mathrm{N}_{2}-150\left(1.8 \Omega \mathrm{cm}^{2}\right)<$ $\mathrm{NiCoSe}_{2}-180\left(2.5 \Omega \mathrm{cm}^{2}\right)<\mathrm{NiCoSe}_{2}-120\left(3.1 \Omega \mathrm{cm}^{2}\right)<\mathrm{Pt}(6.2 \Omega$ 

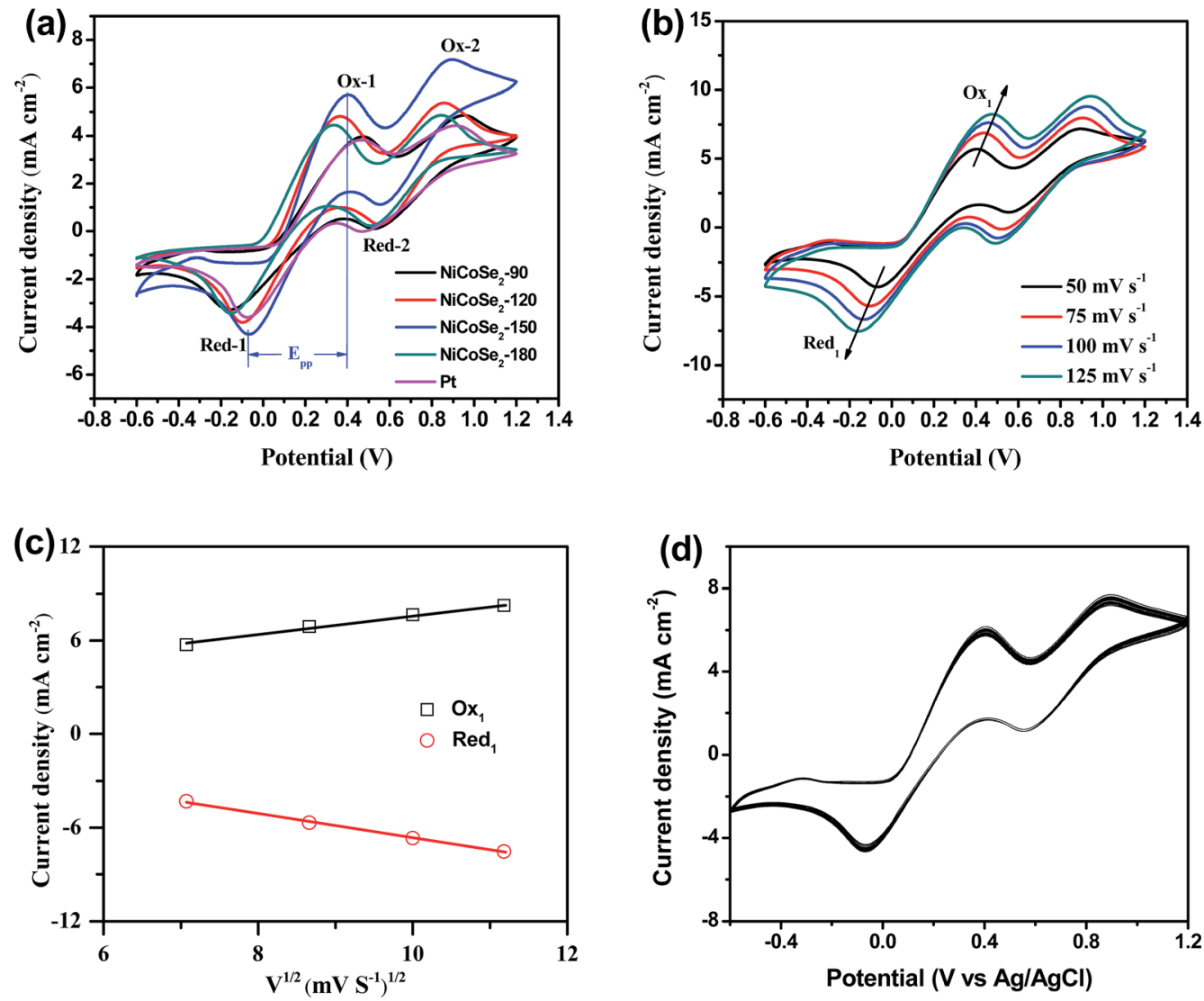

Fig. 4 (a) CV curves of $\mathrm{NiCoSe}_{2}-90, \mathrm{NiCoSe}_{2}-120, \mathrm{NiCoSe}_{2}-150, \mathrm{NiCoSe}_{2}-180$ and $\mathrm{Pt} \mathrm{CEs} \mathrm{for} \mathrm{I}^{-} / \mathrm{I}_{3}^{-}$redox couples at a scan rate of $50 \mathrm{mV} \mathrm{s}^{-1}$, (b) CVs for the $\mathrm{NiCOSe}_{2}-150$ electrode recorded at different scan rates of $50,75,100$ and $125 \mathrm{mV} \mathrm{s}^{-1}$ and (c) the relationship between the redox current density and the square root of scan rates of CVs for $\mathrm{NiCoSe}_{2}-150 \mathrm{CE}$. (d) The 100-stacking CV curves from NiCoSe $2-150 \mathrm{CE}$ at a scan rate of $50 \mathrm{mV} \mathrm{s}^{-1}$

$\left.\mathrm{cm}^{2}\right)<\mathrm{NiCoSe}_{2}-90\left(12.5 \Omega \mathrm{cm}^{2}\right)$, which indicated that the $R_{\mathrm{ct}}$ values of $\mathrm{NiCoSe}_{2}-120, \mathrm{NiCoSe}_{2}-150$ and $\mathrm{NiCoSe}_{2}-180$ were all smaller than that of Pt. It is thus apparent that the abovementioned three devices have higher catalytic activities and charge-transfer abilities than the Pt-based DSSC.

Tafel polarization analysis was carried out to estimate the electrocatalytic activity of the charge-transfer performance of the $\mathrm{I}^{-} / \mathrm{I}_{3}{ }^{-}$redox pair at the $\mathrm{CE} /$ electrolyte interface. Typically, a Tafel curve can be divided into three zones by the value of the overpotential. The region at the lower overpotential of $|U|<$ $0.120 \mathrm{~V}$ represents the polarization zone, the region at the middle potential with a sharp slope represents the Tafel zone, and the region at higher overpotential with the horizontal portion represents the diffusion zone. The exchange current density $\left(J_{0}\right)$ is estimated from the slope of the cathodic or the anodic branch, and the limiting diffusion current density $\left(J_{\lim }\right)$ is the intersection of the anodic branch with the $Y$-axis. $J_{0}$ and $J_{\text {lim }}$ can be obtained from the corresponding Tafel zone and the diffusion zone. ${ }^{34-37}$ As shown in Fig. $5 b, \mathrm{NiCoSe}_{2}-150 \mathrm{CE}$ achieved the highest $J_{0}$ value $\left(10.67 \mathrm{~mA} \mathrm{~cm}^{-2}\right)$ in the Tafel zone, and it exhibited the strongest catalytic activity. The $J_{0}$ values for these electrodes followed the order $\mathrm{NiCoSe}_{2}-150>\mathrm{NiCoSe}_{2}-180$ $>\mathrm{NiCoSe}_{2}-120>\mathrm{Pt}>\mathrm{NiCoSe}_{2}-90$, suggesting that the catalytic activities of CEs could be presented in the same order. In the diffusion region, $\mathrm{NiCOSe}_{2}-120, \mathrm{NiCoSe}_{2}-150$ and $\mathrm{NiCoSe}_{2}-180$ CEs exhibited higher $J_{\text {lim }}$ values compared to Pt, which indicated that these prepared electrodes can achieve higher catalytic activities. $\mathrm{NiCoSe}_{2}-90$ CE showed the lowest $J_{\text {lim }}$ value, which suggested the lowest electrocatalytic ability towards $\mathrm{I}_{3}{ }^{-}$reduction. The trend of $J_{\text {lim }}$ was consistent with that of $J_{0}$ for these

Table 1 Electrochemical parameters obtained from CV, EIS and Tafel characterizations

\begin{tabular}{|c|c|c|c|c|c|c|}
\hline CEs & $E_{\mathrm{pp}}(\mathrm{mV})$ & $\left|J_{\text {Red-1 }}\right|\left(\mathrm{mA} \mathrm{cm}^{-2}\right)$ & $R_{\mathrm{s}}\left(\Omega \mathrm{cm}^{2}\right)$ & $R_{\mathrm{ct}}\left(\Omega \mathrm{cm}^{2}\right)$ & $J_{0}\left(\mathrm{~mA} \mathrm{~cm}^{-2}\right)$ & $J_{\lim }\left(\mathrm{mA} \mathrm{cm}^{-2}\right)$ \\
\hline $\mathrm{NiCoSe}_{2}-90$ & 633 & 3.28 & 9.4 & 12.5 & 1.28 & 33.73 \\
\hline $\mathrm{NiCoSe}_{2}-120$ & 465 & 3.81 & 9.6 & 3.1 & 6.53 & 84.72 \\
\hline $\mathrm{NiCoSe}_{2}-180$ & 487 & 3.43 & 9.5 & 2.5 & 7.41 & 99.54 \\
\hline $\mathrm{Pt}$ & 535 & 3.59 & 9.5 & 6.2 & 5.46 & 79.07 \\
\hline
\end{tabular}



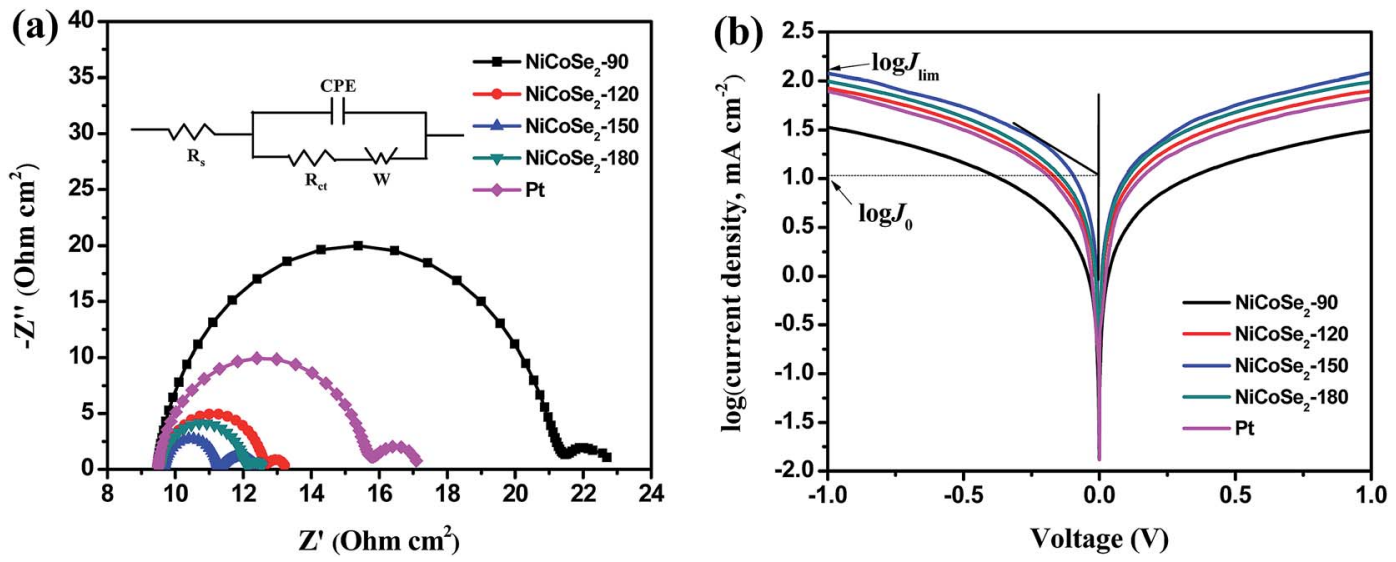

Fig. 5 (a) EIS Nyquist plots and the corresponding equivalent circuit model (inset) and (b) Tafel polarization curves for the symmetric cells fabricated with $\mathrm{NiCoSe}_{2}-90, \mathrm{NiCoSe}_{2}-120, \mathrm{NiCoSe}_{2}-150, \mathrm{NiCoSe}_{2}-180$ and Pt electrodes.

CEs. Additionally, the $J_{0}$ values could be calculated by using eqn (3), and the parameters obtained from the Tafel plots are given in Table 1. Larger $J_{0}$ values result in smaller $R_{\mathrm{ct}}$ values of CEs, which was in agreement with the EIS data. Clearly, the abovementioned CV, EIS, and Tafel polarization measurement results indicated that the $\mathrm{NiCoSe}_{2}-150$ electrode had the highest catalytic activity as a CE compared to the other $\mathrm{NiCoSe}_{2} \mathrm{CEs}$ and Pt CE. In contrast, $\mathrm{NiCoSe}_{2}-120, \mathrm{NiCoSe}_{2}-150, \mathrm{NiCoSe}_{2}-180$ showed higher catalytic activities than Pt and exhibited potentials to achieve reasonably high PCE values.

$$
J_{0}=R T / n F R_{\mathrm{ct}}
$$

here, $R_{\mathrm{ct}}$ is the charge transfer resistance at the $\mathrm{CE} /$ electrolyte interface obtained from the EIS spectra, $F$ is the Faraday's constant, $n$ is the number of electrons involved in the reduction of $\mathrm{I}_{3}{ }^{-}$at the electrode $(n=2), T$ is the temperature $(298 \mathrm{~K})$, and $R$ is the gas constant.

\subsection{Photovoltaic performances}

Fig. 6a shows the $J-V$ curves of DSSCs with $\mathrm{NiCoSe}_{2}$ CEs and Pt $\mathrm{CE}$, and the corresponding photovoltaic parameters (including the open circuit voltage $\left(V_{\text {oc }}\right)$, short circuit current density $\left(J_{\mathrm{sc}}\right)$, fill factor (FF) and PCE) are presented in Table 2. PCE increased in the order $\mathrm{NiCoSe}_{2}-90(7.56 \%)<\mathrm{Pt}(8.22 \%)<\mathrm{NiCoSe}_{2}-180$ $(8.31 \%)<\mathrm{NiCoSe}_{2}-120(8.48 \%)<\mathrm{NiCoSe}_{2}-150$ (8.76\%), which showed that $\mathrm{NiCoSe}_{2}$ alloy CEs exhibited excellent electrocatalytic activities for the reduction of $\mathrm{I}_{3}{ }^{-}$. DSSCs based on $\mathrm{NiCOSe}_{2}-150$ CE showed the highest PCE of $8.76 \%$, the highest $J_{\mathrm{sc}}$ of $17.82 \mathrm{~mA} \mathrm{~cm}^{-2}, V_{\mathrm{oc}}$ of $0.770 \mathrm{~V}$ and FF of 0.638 . DSSCs with $\mathrm{NiCOSe}_{2}-90$ CE showed distinct lowest PCE and a $J_{\mathrm{sc}}$ value of $15.65 \mathrm{~mA} \mathrm{~cm}{ }^{-2}$. The DSSC with $\mathrm{NiCoSe}_{2}-120$ exhibited higher $J_{\mathrm{sc}}$ and PCE values compared to $\mathrm{NiCoSe}_{2}-90$. In addition, the DSSC with $\mathrm{NiCoSe}_{2}-180 \mathrm{CE}$ also exhibited remarkable electrocatalytic activity with high PCE and a $J_{\mathrm{sc}}$ value of $17.08 \mathrm{~mA} \mathrm{~cm} \mathrm{~cm}^{-2}$; these values were slightly higher than those of Pt.

To analyse the differences between the $J_{\mathrm{sc}}$ values of these devices, the IPCE responses as a function of the incident wavelength are plotted in Fig. 6b. The IPCE plot of the DSSC based on $\mathrm{NiCoSe}_{2}-150$ covers a broad wavelength range from $400 \mathrm{~nm}$ to $800 \mathrm{~nm}$ with an IPCE maximum value of $89.9 \%$ at $530 \mathrm{~nm}$, and this value matches well with the absorption result of the commercial N719 dye. Moreover, the order of the IPCE values for these devices is $\mathrm{NiCoSe}_{2}-150>\mathrm{NiCoSe}_{2}-120>$ $\mathrm{NiCoSe}_{2}-180>\mathrm{Pt}>\mathrm{NiCoSe}_{2}-90$, which agrees well with the $J_{\text {sc }}$ order. With the increase in the hydrothermal temperature, PCEs
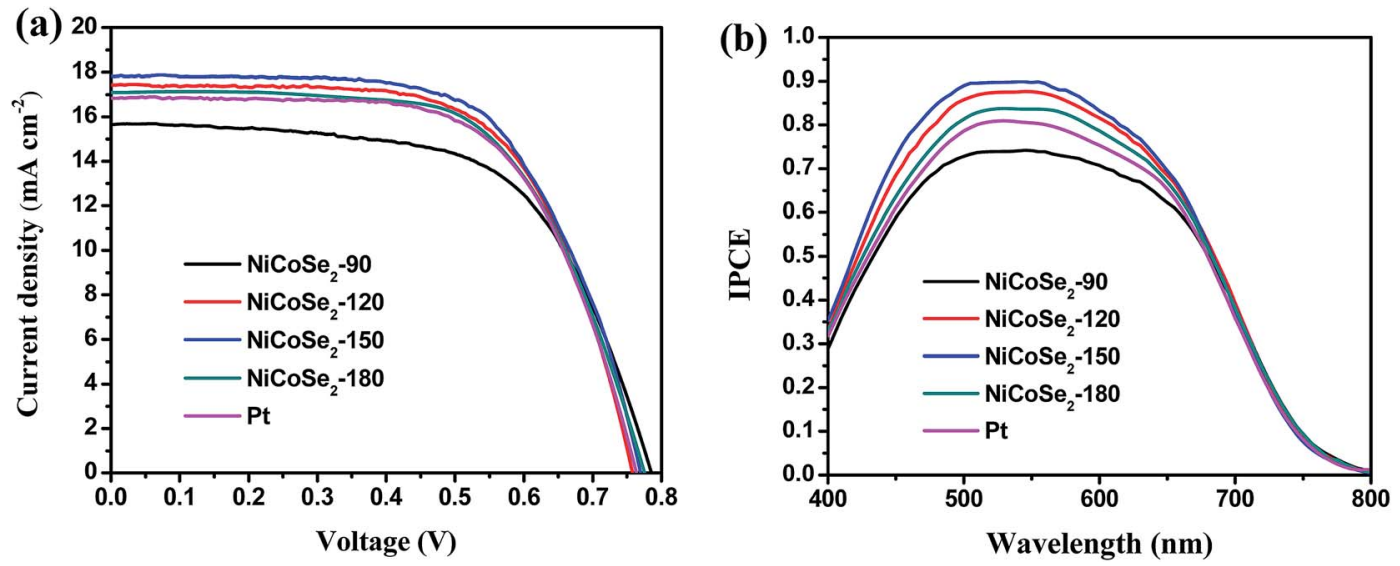

Fig. 6 (a) J-V curves (b) IPCE curves of DSSCs with $\mathrm{NiCoSe}_{2}-90, \mathrm{NiCoSe}_{2}-120, \mathrm{NiCoSe}_{2}-150, \mathrm{NiCoSe}_{2}-180$ and Pt-based CEs. 
Table 2 Photovoltaic data of DSSCs with $\mathrm{NiCoSe}_{2}-90, \mathrm{NiCoSe}_{2}-120, \mathrm{NiCoSe}_{2}-150, \mathrm{NiCoSe}_{2}-180$ and Pt-based CEs

\begin{tabular}{lllll}
\hline CEs & $V_{\text {oc }}(\mathrm{V})$ & $J_{\text {sc }}\left(\mathrm{mA} \mathrm{cm}^{-2}\right)$ & FF & PCE $(\%)$ \\
\hline NiCoSe $_{2}-90$ & $0.786 \pm 0.014$ & $15.65 \pm 0.011$ & $0.615 \pm 0.010$ & $7.56 \pm 0.25$ \\
NiCoSe $_{2}-120$ & $0.760 \pm 0.012$ & $17.44 \pm 0.011$ & $0.640 \pm 0.011$ & $8.48 \pm 0.24$ \\
NiCoSe $_{2}-150$ & $0.770 \pm 0.008$ & $17.82 \pm 0.007$ & $0.638 \pm 0.009$ & $8.76 \pm 0.22$ \\
NiCoSe $_{2}-180$ & $0.774 \pm 0.012$ & $17.08 \pm 0.011$ & $0.628 \pm 0.010$ & $8.31 \pm 0.26$ \\
Pt & $0.765 \pm 0.010$ & $16.84 \pm 0.008$ & $0.637 \pm 0.009$ & $8.22 \pm 0.21$
\end{tabular}

of $\mathrm{NiCoSe}_{2}$-based DSSCs increase first and then decrease with a maximum value of $8.76 \%$. The high IPCE value and the broader absorption of $\mathrm{NiCoSe}_{2}-150$ explain the high $J_{\mathrm{sc}}$ value from the $J-V$ measurement. The slightly higher efficiency observed for $\mathrm{NiCoSe}_{2}-150$ is mainly due to relatively larger $J_{\mathrm{sc}}$ value, which can be due to the efficient reduction of $\mathrm{I}_{3}{ }^{-}$and the reduced charge transfer resistance at the $\mathrm{CE} /$ electrolyte interface. $\mathrm{NiCoSe}_{2}-150 \mathrm{CE}$ exhibits superior morphology, which is beneficial to enhance its catalytic activity.

\section{Conclusions}

In conclusion, ternary $\mathrm{NiCoSe}_{2}$ alloy-based shape-controllable microspheres with a uniform size were synthesized via a simple hydrothermal method. Tuning the hydrothermal temperature could program the shape and the size of $\mathrm{NiCoSe}_{2}$ microspheres. The size of the resultant $\mathrm{NiCoSe}_{2}$ microspheres increased with the increasing temperature. Also, the interior of $\mathrm{NiCoSe}_{2}-150$ possessed a flocculent structure. Subsequently, the synthesized $\mathrm{NiCoSe}_{2}$ microspheres were deposited on FTO glass to prepare low-cost and high-performance CEs for DSSCs. The DSSCs based on $\mathrm{NiCoSe}_{2}-120$ and $\mathrm{NiCoSe}_{2}-150$ CEs exhibited PCEs of $8.48 \%$ and $8.76 \%$, respectively, which were higher than that of the DSSC with Pt CE (8.31\%). The CV and EIS tests indicated that $\mathrm{NiCoSe}_{2}-$ $150 \mathrm{CE}$ achieved the highest catalytic activity and the lowest charge transfer resistance at the CE/electrolyte interface for the reduction of $\mathrm{I}_{3}{ }^{-} / \mathrm{I}^{-}$compared to the other NiCoSe $\mathrm{NEs}_{2} \mathrm{CEnd} \mathrm{Pt} \mathrm{CE}$; these results agreed with the results of the photovoltaic analysis. This research indicates that $\mathrm{NiCoSe}_{2}$ microspheres can be used as low-cost and highly efficient CEs in DSSCs.

\section{Conflicts of interest}

The authors declare no conflict of interest.

\section{Acknowledgements}

This work was supported by the National Natural Science Foundation of China (Grant No. 11747001), the Scientific Research Fund of Jiangsu Provincial Education Department (Grant No. 17KJB140029, 17KJD240002), the Key Applied Basic Research Program of Yunnan Province (Grant No. 2017FA024), and Program for Innovative Research Team (in Science and Technology) in University of Yunnan Province.

\section{References}

1 B. O'Regan and M. Grätzel, Nature, 1991, 353, 737-740.
2 A. Heller, Nature, 2001, 414, 338-344.

3 A. Yella, H. W. Lee, H. N. Tsao, C. Yi, A. K. Chandiran, M. K. Nazeeruddin, E. W. Diau, C. Y. Yeh, S. M. Zakeeruddin and M. Grätzel, Science, 2011, 334, 629634.

4 F. Gong, H. Wang, X. Xu, G. Zhou and Z. S. Wang, J. Am. Chem. Soc., 2012, 134, 10953.

5 W. Wang, X. Pan, W. Liu, B. Zhang, H. Chen, X. Fang, J. Yao and S. Dai, Chem. Commun., 2014, 50, 2618-2620.

6 X. Xin, M. He, W. Han, J. Jung and Z. Lin, Angew. Chem., 2011, 50, 11739-11742.

7 C. T. Lee, J. D. Peng, C. T. Li, Y. L. Tsai, R. Vittal, K. C. Ho, C. T. Lee, C. T. Li, Y. L. Tsai and R. Vittal, Nano Energy, 2014, 10, 201-211.

8 Q. Yang, P. Yang, J. Duan, X. Wang, L. Wang, Z. Wang and Q. Tang, Electrochim. Acta, 2016, 190, 85-91.

9 H. Li, Q. Tang, Y. Meng, B. He and L. Yu, Electrochim. Acta, 2016, 190, 409-418.

10 H. Wang, W. Wei and Y. H. Hu, J. Mater. Chem. A, 2013, 1, 6622-6628.

11 X. Zheng, J. Guo, Y. Shi, F. Xiong, W. H. Zhang, T. Ma and C. Li, Chem. Commun., 2013, 49, 9645-9647.

12 J. Chen, K. Li, Y. Luo, X. Guo, D. Li, M. Deng, S. Huang and Q. Meng, Carbon, 2009, 47, 2704-2708.

13 C. Bu, Y. Liu, Z. Yu, S. You, H. Niu, L. Liang and X. Z. Zhao, ACS Appl. Mater. Interfaces, 2013, 5, 7432-7438.

14 J. Yao, K. Zhang, W. Wang, X. Zuo, Q. Yang, H. Tang, M. Wu and G. Li, Nanoscale, 2018, 10, 7946-7956.

15 B. Yang, X. Zuo, P. Chen, L. Zhou, X. Yang, H. Zhang, G. Li, M. Wu, Y. Ma, S. Jin and X. Chen, ACS Appl. Mater. Interfaces, 2015, 7, 137-143.

16 M. Dinari, M. M. Momeni and M. Goudarzirad, J. Mater. Sci., 2016, 51, 2964-2971.

17 R. Li, Q. Tang, L. Yu, X. Yan, Z. Zhang and P. Yang, J. Power Sources, 2016, 309, 231-237.

18 X. Chen, Q. Yang, Q. Meng, Z. Zhang, J. Zhang, L. Liu, X. Zhang and P. Yang, Sol. Energy, 2017, 144, 342-348.

19 X. Qian, H. Li, L. Shao, X. Jiang and L. Hou, ACS Appl. Mater. Interfaces, 2016, 8(43), 29486-29495.

20 H. Li, X. Qian, C. Zhu, X. Jiang, L. Shao and L. Hou, J. Mater. Chem. A, 2017, 5(9), 4513-4526.

21 X. Zhang, M. Zhen, J. Bai, S. Jin and L. Liu, ACS Appl. Mater. Interfaces, 2016, 8, 17187.

22 J. Theerthagiri, R. A. Senthil, M. H. Buraidah, M. Raghavender, J. Madhavan and A. K. Arof, J. Solid State Chem., 2016, 238, 113-120.

23 L. Shao, X. Qian, H. Li, C. Xu and L. Hou, Chem. Eng. J., 2017, $315,562-572$. 
24 H. Sun, L. Zhang and Z. S. Wang, J. Mater. Chem. A, 2014, 2, 16023-16029.

25 H. Chen, J. Jiang, Y. Zhao, L. Zhang, D. Guo and D. Xia, J. Mater. Chem. A, 2014, 3, 428-437.

26 X. Xiong, G. Waller, D. Ding, D. Chen, B. Rainwater, B. Zhao, Z. Wang and M. Liu, Nano Energy, 2015, 16, 71-80.

27 W. Wei, L. Mi, Y. Gao, Z. Zheng, W. Chen and X. Guan, Chem. Mater., 2014, 26, 3418-3426.

28 B. Liu, D. Kong, J. Zhang, Y. Wang, T. Chen, C. Cheng and H. Y. Yang, J. Mater. Chem. A, 2016, 4, 3287-3296.

29 I. H. Kwak, H. S. Im, D. M. Jang, Y. W. Kim, K. Park, Y. R. Lim, E. H. Cha and J. Park, ACS Appl. Mater. Interfaces, 2016, 8, 5327.

30 S. Yun, H. Zhang, H. Pu, J. Chen, A. Hagfeldt and T. Ma, Adv. Energy Mater., 2013, 3, 1407-1412.
31 W. Hou, Y. Xiao, G. Han and H. Zhou, Electrochim. Acta, 2016, 190, 720-728.

32 X. Qian, Y. Z. Zhu, W. Y. Chang, J. Song, B. Pan, L. Lu, H. H. Gao and J. Y. Zheng, ACS Appl. Mater. Interfaces, 2015, 7, 9015.

33 X. Qian, L. Shao, H. Li, R. Yan, X. Wang and L. Hou, J. Power Sources, 2016, 319, 39-47.

34 E. Bi, H. Chen, X. Yang, W. Peng, M. Grätzel and L. Han, Energy Environ. Sci., 2014, 7, 2637-2641.

35 S. Yun, A. Hagfeldt and T. Ma, ChemInform, 2015, 45, 62106237.

36 J. Y. Lin, C. Y. Chan and S. W. Chou, Chem. Commun., 2013, 49, 1440-1442.

37 L. Kavan, J. H. Yum, M. K. Nazeeruddin and M. Grätzel, ACS Nano, 2011, 5, 9171-9178. 